\title{
Institutionalizing impact evaluation within the framework of a monitoring and evaluation system
}

\section{Michael Bamberger (org.)}

Sponsored by the World Bank's Independent Evaluation Group (IEG) and the Poverty Analysis, Monitoring and Impact Evaluation Thematic Group of the World Bank.

50 p., 2009

700 19th Street, N.W.

Washington, DC 20431, U.S.A.

\section{Maria Beatriz Machado Bonacelli}

Professora do Departamento de Política Científica e Tecnológica da Universidade Estadual de Campinas (Unicamp) e Pesquisadora Associada do Grupo de Estudos sobre Organização da Pesquisa e da Inovação (Geopi/DPCT/Unicamp)

As motivações para a realização de trabalhos de avaliação vêm ganhando novos contornos em diversas áreas do conhecimento e da economia em geral. Sua crescente importância em diversos fóruns e com diferentes propósitos e a evolução dos métodos de avaliação são resultado do refinamento das inquietações referentes à formulação de ações de intervenção, à correção de rumos de políticas e programas, à prestação de contas a diferentes interessados e envolvidos nessas ações, entre outros.

Esse quadro não é diferente no que diz respeito aos trabalhos em Ciência, Tecnologia e Inovação (CT\&I). Está em curso um franco amadurecimento das questôes relacionadas à avaliação em CT\&I, pertinente à evolução do entendimento sobre a natureza e a organização dessas atividades e sobre os potenciais benefícios dos investimentos para a sociedade. O elemento primordial deste quadro é que se 
reconhece cada vez mais o caráter coletivo do processo de desenvolvimento da CT\&I, dependente de diferentes competências e da governança de uma gama importante de atores, sob a forte presença de políticas públicas - via políticas e programas voltados ao suporte à pesquisa e desenvolvimento $(\mathrm{P} \& \mathrm{D})$ e orientados pelo Estado.

Desta forma, os trabalhos de avaliação em CT\&I e em P\&D são vistos como instrumento de aprendizado, planejamento e gestão dessas atividades, de orientação dos caminhos seguidos ou a seguir (e a correção de rumos), assim como de accountability (prestação de contas) para stakeholders, governo e mesmo para a sociedade em geral.

Com o passar do tempo e o amadurecimento da compreensão do cenário de reprodução das ações em CT\&I, como dito anteriormente, foi se percebendo a necessidade de monitorar e avaliar não apenas os insumos alocados (inputs) - recursos humanos e financeiros, por exemplo -, mas também os resultados das pesquisas (outputs) - produção científica e tecnológica -, chegando-se à avaliação de impactos.

A avaliação de impacto consiste em avaliar os efeitos decorrentes dos resultados de uma política, de um programa e/ou de um projeto. Resultado é a consecução dos objetivos previstos inicialmente numa política/programa/projeto. Portanto, impacto é o efeito do resultado. A avaliação de impactos permite que se observe o alcance dos trabalhos para além do local de sua idealização e de suas primeiras aplicações e implicações. Os métodos de avaliação de resultados estão mais consolidados e sua difusão na literatura já é ampla, diferentemente dos trabalhos de avaliação de impactos.

Identificar os efeitos dos resultados da ação (de P\&D, por exemplo) envolve rastrear os caminhos que suas atividades percorreram, incluindo aqueles que não foram previstos inicialmente, o que coloca a dificuldade de se "enxergar" (e de se limitar) o alcance do impacto. Soma-se a isso o elemento de atribuição de causa e efeito, dado que outros fatores podem ter concorrido para que os efeitos dos resultados de um determinado projeto de P\&D (ou seja, os impactos) se efetivassem.

Abordagens metodológicas de avaliação de impacto, em geral, têm por objetivo determinar se certo conjunto de ações tem produzido os efeitos desejados na sociedade e se estes são atribuíveis à ação do objeto de avaliação. Neste sentido, as avaliaçôes de impacto consideram os efeitos que perduram ao longo do tempo com uma perspectiva que vai além dos beneficiários direitos ou dos participantes das ações que compõem o objeto de avaliação, devendo integrar os diversos atores que participam (ou possam participar) de um projeto de pesquisa.

Internalizar esse processo não é tarefa fácil, nem para empresas, nem para organismos governamentais, ou qualquer tipo de organização. Diante disso, o Banco 
Mundial produziu um documento bastante minucioso, mas de fácil interpretação, no qual são apresentados elementos a serem considerados para dar conta do desafio de criar, implementar e institucionalizar o processo (e mesmo a cultura) de avaliação de impactos, situando-o num ambiente mais amplo, intitulado Sistema de Monitoramento e Avaliação.

A obra Institutionalizing impact evaluation within the framework of a monitoring and evaluation system, organizada por Michael Bamberger, foi apoiada institucional e financeiramente pelo Independent Evaluation Group (IEG) e the Poverty Analysis, Monitoring and Impact Evaluation Thematic Group, do Banco Mundial.

A publicação aponta e argumenta a importância de se construir um arcabouço sistemático para o processo de avaliação de impactos (AI, em português, ou IE em inglês) em diferentes instituições, integrado às especificidades delas, indo além dos trabalhos ad hoc - que podem ser oportunistas, dependentes da liberação de recursos e ligados a interesses obscuros, ou seja, atrelados a outras variáveis que não são do interesse do processo de avaliação. Propóe-se a integração entre avaliação de impactos e ações de monitoramento, criando assim um verdadeiro sistema para coordenar, monitorar, organizar, avaliar e corrigir rotas de políticas, programas e projetos os mais diversos. Recentemente esta proposta de integração tem sido chamada também de avaliação continuada, que mescla os instrumentos de avaliação de impactos e monitoramento.

Para tal, faz-se necessário planejamento orçamentário e formulação de políticas e instrumentos de gestão e accountability. Acredita-se que casos exitosos de avaliação proporcionam melhoria da eficiência e efetividade de programas, contribuem para a formulação de políticas futuras, fortalecem o planejamento orçamentário e a gestão financeira de projetos e promovem uma racionalidade rigorosa e transparente para a continuidade ou descontinuidade de um programa.

A brochura, de 50 páginas, é fortemente favorável à adoção do método contrafactual, ou seja, a comparação entre um grupo que recebeu e outro que não recebeu uma intervenção - para responder "o que teria sido se não tivesse acontecido?”. Veja-se esta passagem (página 10), a qual apresenta também a definição de avaliação de impactos:

The World Bank PovertyNet Web site defines IE as an evaluation that [...] assesses changes in the well-being of individuals, households, communities or firms that can be attributed to a particular project, program, or policy. The central impact evaluation question is what would have happened to those receiving the 
intervention if they had not in fact received the program. Since we cannot observe this group both with and without the intervention, the key challenge is to develop a counterfactual - that is, a group which is as similar as possible (in observable and unobservable dimensions) to those receiving the intervention. This comparison allows for the establishment of definitive causality - attributing observed changes in welfare to the program, while removing confounding factors.

Tal modelo tem sido considerado a regra de ouro pelas agências de fomento internacionais, mas se aplica bem a alguns casos e a outros não.

A partir desse ponto de vista, o livro apresenta vários elementos para a realização da avaliação de impactos integrada a um sistema de monitoramento. São detalhados aspectos a serem considerados em trabalhos de avaliação de impactos, mas chama-se atenção para a dificuldade de sua implementação de forma sistemática e continuada por diferentes instituições, devido a vários motivos: desde financeiros - não é barata a constituição de um processo de avaliação, ainda mais pensando-se num sistema de monitoramento e avaliação (M\&E System) - , até aspectos políticos e administrativos (a quem interessa a avaliação de um projeto e/ou de um programa, ainda mais em períodos de transição ou mudança administrativa) e mesmo de coordenação dos trabalhos de avaliação de impactos (por exemplo, falta de entrosamento ou comunicação entre a gestão do programa e a equipe de avaliação, com ausência de informações essenciais - dados, registros, publicações do programa a serem levantados, analisados e discutidos para um maior conhecimento do objeto a ser avaliado), entre outros.

A partir do sumário da publicação, os desafios e as oportunidades da internalização de um M\&E System se expõem: a institucionalização da AI; a criação de demanda para AI; o desenvolvimento da capacitação em AI; levantamento e análise de dados e informaçôes para AI; e a promoção da AI.

Mesmo fazendo uma grande defesa dos trabalhos de avaliação de impactos, a obra reforça que AI é um dos vários tipos de avaliação a serem usados por gestores, planejadores e policymakers - ela responde a alguns tipos de questão, mas não a todas - e faz sentido se outros instrumentos a sustentarem (aqui, um sistema de monitoramento das ações). Além disso, devem ser observados o estágio em que se encontram os programas e projetos a serem avaliados - muitas vezes, a avaliação de resultados é mais conveniente do que a de impactos - e ainda a complexidade dos mesmos - uma avaliação mais simples e pontual pode servir aos propósitos de um levantamento e análise, considerando-se que os trabalhos de avaliação de im- 
pactos geralmente exigem recursos humanos e financeiros, tempo e competências não desprezíveis.

O Geopi (Grupo de Estudos sobre Organização da Pesquisa e da Inovação), do Departamento de Política Científica e Tecnológica (DPCT), da Unicamp, se colocou o desafio de desenvolver metodologia de avaliação de impactos, já no final dos anos 1990, e, mais recentemente, de implementar avaliação continuada (de resultado e impacto) em agência de fomento à C\&T. Conceitual, analítica e metodologicamente avançou-se fortemente desde então, com a colaboração de inúmeros especialistas e com o envolvimento de muitos alunos, os quais já têm replicado tais avanços em programas e projetos em diversas situaçóes. ${ }^{1}$

A metodologia comporta dois momentos: um primeiro, que faz análise profunda e detalhada do objeto, visando a identificação dos impactos potenciais; e um segundo momento, em que se procura medir a intensidade deste impacto. Esses momentos podem ser resumidos basicamente como a conjugação de dois métodos em sua essência: Método de Decomposição (dado que o objeto será "decomposto" em seus vários objetivos) e Método de Adicionalidade Associada à Atribuição de Causalidade (para que seja possível avaliar o real impacto do programa). Agregam-se, ainda, métodos e ferramentas ad hoc a partir das necessidades do programa/projeto em avaliação. ${ }^{2} \mathrm{O}$ desafio maior hoje é o de justamente criar a cultura da avaliação no âmbito das organizaçôes envolvidas com CT\&I, demonstrando sua pertinência e relevância em várias situações, quebrando rotinas e indicando a necessidade de comunicação e transparência desde a constituição de programas e projetos até o encerramento deles (e mesmo por algum tempo depois disso).

Certamente a obra do Banco Mundial é uma referência que vem contribuir para o aprimoramento de métodos de avaliação de impactos em diversos campos do conhecimento, mas, por sua vez, os trabalhos de organismos como esse também podem se valer muito do que tem sido feito por outros grupos estudiosos do assunto. Todos nós só teremos a ganhar com isso.

1 Um dos principais parceiros do GEOPI em seus estudos e projetos e também no desafio da avaliação continuada tem sido a Embrapa, uma das instituições mais respeitadas no país por sua experiência de implementação de avaliação institucionalizada que inclui o monitoramento e a avaliação de impactos de seus centros de pesquisa e de suas tecnologias e cultivares desenvolvidas.

2 Os trabalhos sobre avaliação de resultados e de impactos (relatórios de pesquisa, teses, dissertações e publicações) do Geopi/DPCT podem ser encontrados em <www.ige.unicamp.br/geopi>. 

Os trabalhos submetidos à RBI devem enquadrar-se na linha editorial da Revista e observar as normas e orientações indicadas abaixo. Os artigos são avaliados no sistema double-blind review por pelo menos dois pareceristas, ambos de instituições distintas daquela a qual o (s) autor (es) está (ao) vinculado (s). Os direitos autorais dos trabalhos aprovados são automaticamente transferidos à RBI como condição para sua publicação.

1. A RBI publica artigos e resenhas, assim como reedita clássicos e documentos históricos relacionados à temática da Revista. Os artigos devem ser encaminhados via Sistema Eletrônico de Editoração de Revistas (SEER) e as resenhas devem ser encaminhadas por e-mail para o endereço <rbi@ige.unicamp.br>.

2. Podem ser submetidos trabalhos redigidos em português, inglês ou espanhol.

3. Os artigos devem ser submetidos pelo SEER SEM identificação dos autores. Para tanto, é necessário que os autores, no momento da submissão do artigo, preencham suas informações corretamente no sistema.

4. Os trabalhos devem ser digitados no editor de texto Word 6.0 ou posterior; fonte: times new roman; corpo: 12; margens direita, superior e inferior: $2,5 \mathrm{~cm}$; margem esquerda: $3 \mathrm{~cm}$; espaçamento entrelinhas: 1,5; e alinhamento justificado. Os artigos não devem ultrapassar 10.000 palavras e as resenhas não devem exceder 2.500 palavras.

5. Os artigos devem ser submetidos contendo:

5.1. resumo e título em português ou espanhol e abstract e title em inglês com no máximo 150 palavras;

5.2. até cinco palavras-chave, também em português ou espanhol e em inglês.

5.3. classificação do artigo segundo o Classification System for Journal Articles do Journal of Economic Literature.

6. As citações devem ser abreviadas no corpo do texto e em notas de pé-de-página (autor, ano da publicação e, quando for o caso, página) completas nas referências no final do texto, segundo as normas para apresentação de trabalhos técnico-científicos da ABNT Associação Brasileira de Normas Técnicas. 
